\title{
Primary hyperparathyroidism: the case for medical management
}

\author{
W VAN'T HOFF, F W BALLARDIE, E J BICKNELL
}

\begin{abstract}
Thirty two patients with primary hyperparathyroidism were followed up medically for a mean of $4 \cdot 2$ years. One patient had an operation because of a rise in plasma calcium concentration. There was no significant change in the mean plasma calcium and creatinine concentrations or in blood pressure during the period of follow up. The progress of these patients who were managed medically was compared with that of a group of 60 patients who had had successful operations for primary hyperparathyroidism. There was no significant change in mean plasma creatinine concentration or in blood pressure in the group who had had operations during a mean follow up period of 5.9 years.

The natural history of mild asymptomatic hyperparathyroidism is probably different from and better than that of the type of hyperparathyroidism that was usually seen before the advent of routine chemical screening. It is suggested that patients over the age of 60 with mild asymptomatic hyperparathyroidism, and perhaps even younger patients, may not require operation.
\end{abstract}

\footnotetext{
Department of Endocrinology, North Staffordshire Hospital Centre, Stoke-on-Trent ST4 7LN

W VAN'T HOFF, MB, FRCP, consultant physician

F W BALLARDIE, PHD, MRCP, registrar

E J BICKNELL, BSC, biochemist

Correspondence to: Dr W van't Hoff.
}

\section{Introduction}

Primary hyperparathyroidism used to be diagnosed relatively rarely and usually in departments and centres where there was a particular interest in the condition. Although the diagnosis could be difficult to make and management was often not easy, operation was almost invariably recommended.

The advent of automated measurement of serum chemistry in the past 15 years has changed this. The incidence of primary hyperparathyroidism in hospital populations has variously been found to be 1 in $2000,{ }^{1} 1$ in $1000,{ }^{2}$ and 1 in $680 .{ }^{3}$ In Rochester, Minnesota, the annual rate of diagnosis per 100000 population increased from the previous rate of 7.8 to 51.1 in $1974-5$, the first year that chemical screening was introduced. It fell to $27 \cdot 7$ the following year, which is probably a truer reflection of the present annual rate. ${ }^{4}$ The incidence in this country is about 25 per 100000 population, ${ }^{5}$ and it has been suggested that in England about 10000 cases of primary hyperparathyroidism are diagnosed a year. ${ }^{6}$

Not only has there been a dramatic change in the apparent incidence of hyperparathyroidism, but there has also been a change in its presentation. In the early days patients with hyperparathyroidism had bone disease, and then renal stones became the commonest mode of presentation. ${ }^{7}$ Currently, most patients have no symptoms referable to hyperparathyroidism. ${ }^{5} 8$

It is important to ascertain the cause of this apparent increased incidence of primary hyperparathyroidism. If the true incidence has increased then the disease is being diagnosed at a much earlier stage. There does not, however, seem to be an increase in the more florid type of hyperparathyroidism. The alternative explanation may be not that hyperparathyroidism is becoming more common but that the mild and frequently asymptomatic form of the disease is at one end of the range of hyperparathyroidism and was rarely manifest before the advent of routine chemical screening. If this explanation is correct 
inen possibiy these patients may not progress to develop renal failure and hypertension as has been suggested. ${ }^{9}$

The apparently benign course of several patients with primary hyperparathyroidism who had either declined operation or in whom operation had not been successful prompted us to follow up a number of patients medically, and we compared their progress with that of a group of patients treated by operation.

\section{Patients}

Thirty two patients with primary hyperparathyroidism were followed up medically for a mean of $4 \cdot 2$ years (range $0 \cdot 5-12$ ). The criteria for diagnosis were the presence of hypercalcaemia for which no other cause had been found either at the time of diagnosis or subsequently, and a raised serum parathyroid hormone concentration. None had radiological evidence of bone disease. Mean urine calcium excretion was $7.47 \mathrm{mmol}(299 \mathrm{mg}) / 24$ hours. Only six patients had a calcium excretion of less than $5.0 \mathrm{mmol}(200 \mathrm{mg}) / 24$ hours, and in five of these patients the plasma creatinine concentration was raised. Familial hypocalciuric hypercalcaemia could not be excluded in the other patient, although there was no positive family history. Primary hyperparathyroidism was diagnosed in 27 of the 32 patients after the chance discovery of hypercalcaemia on a routine chemical screening while they were attending the hospital. Four patients presented with renal colic and one with pancreatitis. The mean age of the 32 patients was 59.8 years (range 25-74), and 29 were women. Five patients had refused operation, and in five other patients the decision regarding operation was deferred for various reasons. Two of the patients who had refused operation and one in whom the decision was deferred had had previous negative explorations. In 22 patients a decision was taken not to advise operation. Twelve of these patients were well: the hypercalcaemia was mild and had been a chance finding, and the patients had no symptoms referable to hyperparathyroidism. The 10 other patients were mostly elderly and had ischaemic or other cardiovascular or cerebrovascular disease, and we thought that hyperparathyroidism played either no part or only a minor part in their disease.

The progress of these 32 patients was compared with that of a group of 60 patients who had had successful operations for primary hyperparathyroidism. The mean age of this group was 49.8 years and the mean follow up time after operation 5.9 years (range $0.5-18$ ).

\section{Results}

Twenty of the 32 patients treated medically remained well without operation. Three patients were referred for operation. In two of these, aged 25 and 43, the only reason was their age. We were hesitant at this stage in not advising surgery in view of their long life expectancy. Nevertheless, during the four and seven years, respectively, that they had been followed up before operation their plasma calcium concentration had not increased and renal function and blood pressure had remained normal. The third patient, aged 49 years, who had been hypertensive for 14 years after her pregnancy, was referred for operation after two years because of a rise in plasma calcium concentration.

Three patients died. Two aged 70 and 72 had not been considered for operation because they had had recent cardiac infarcts. Both died from further cardiac infarcts. The third patient, aged 73 , had in the past had a pituitary tumour removed and died of carcinoma of the duodenum.

The condition of six patients at follow up was only fair; their mean age was 70 . Five suffered from severe cardiovascular or cerebrovascular disease, and at diagnosis four had not been well enough to be considered for operation. The sixth patient, whose original plasma calcium concentration was $3.3 \mathrm{mmol} / 1(13.2 \mathrm{mg} / 100 \mathrm{ml})$, had refused operation and was then followed up for 12 years. She developed acute pancreatitis followed by diabetes mellitus and impaired renal function, but there was no further increase in plasma calcium concentration. At the time of writing she was aged 75 and her condition had deteriorated over the previous two years.

\section{BLOOD PRESSURE}

Blood pressure changes in the group treated medically were difficult to assess because most patients with hypertension were treated with hypotensive drugs, which made it impossible to assess their true blood pressures. Four patients were receiving hypotensive treatment at the beginning of the study, and a further seven were subsequently given treatment. If these 11 patients are omitted the mean blood pressure at diagnosis was $143 / 86 \mathrm{~mm} \mathrm{Hg}$; in nine patients mean blood pressure after they had been followed up for six years was $144 / 88 \mathrm{~mm} \mathrm{Hg}$.

If patients receiving hypotensive treatment are included and hypertension is defined as a blood pressure above an arbitrary figure of $150 \mathrm{~mm} \mathrm{Hg}$ systolic or $100 \mathrm{~mm} \mathrm{Hg}$ diastolic, or both, $34.3 \%$ of patients had hypertension at diagnosis and $50 \%$ at the time of follow up. This difference was not significant, and there was no significant difference between these patients and the 60 patients who were followed up after operation (table I).

\begin{tabular}{|c|c|c|c|c|}
\hline \multirow{2}{*}{ Group } & \multirow{2}{*}{$\begin{array}{c}\text { No of } \\
\text { patients }\end{array}$} & \multicolumn{3}{|c|}{ Hypertension } \\
\hline & & At presentation & & At follow up \\
\hline Medical & 32 & $11\left(34 \cdot 3{ }^{\prime \prime}\right)$ & NS & $\begin{array}{c}16\left(50{ }^{\prime \prime},\right) \\
\text { NS }\end{array}$ \\
\hline Surgical & 60 & $18(30 \ldots)$ & NS & $21\left(35{ }^{\prime \prime \prime}\right)$ \\
\hline
\end{tabular}

$N S=$ Not significant

The patients in the medical group were 10 years older than those in the surgical group at the time of diagnosis. As blood pressure rises with age we related the patients' blood pressures both at the time of diagnosis and at the end of their follow up period to the pressures found in a normal population. ${ }^{10}$ For the purposes of this comparison we regarded as hypertensive any patients whose blood pressure (either systolic or diastolic) was $10 \mathrm{~mm} \mathrm{Hg}$ or more above the mean for their age and sex (table II). Patients taking hypotensive drugs were regarded as hypertensive. There was no significant change in blood pressure during the period of follow up in either the medical or the surgical group, or between the two groups.

TABLE II-Proportions of patients with hypertension (defined as blood pressure of $10 \mathrm{~mm} \mathrm{Hg}$ or more systolic or diastolic, or both, above mean for age and sex $\left.{ }^{10}\right)$, including patients receiving hypotensive treatment. ( $\chi^{2}$ test with one degree of freedom)

\begin{tabular}{lcccc}
\hline \multirow{2}{*}{ Group } & No of & \multicolumn{3}{c}{ Hypertensive } \\
\cline { 3 - 5 } & patients & At presentation & At follow up \\
\hline Medical & 32 & $9\left(28 \cdot 1^{\prime \prime}\right)$ & NS & $14\left(43 \cdot 7^{\prime \prime}\right)$ \\
Surgical & 60 & $22\left(36 \cdot 7^{\prime \prime}\right)$ & NS & $22\left(36 \cdot 7^{\prime \prime}\right)$ \\
\hline
\end{tabular}

NS $=$ Not significant.

\section{RENAL FUNCTION}

Glomerular function as measured by clearance studies falls significantly with age, ${ }^{11}$ and creatinine clearance shows large daily variations. ${ }^{12}$ We, therefore, used plasma creatinine concentration as the most suitable measure of change in renal function for a longitudinal study.

The mean plasma creatinine concentration at the time of diagnosis in the medical group was $93.7 \mu \mathrm{mol} / 1.06 \mathrm{mg} / 100 \mathrm{ml})$ and at follow up $96.0 \mu \mathrm{mol} / 1(1.09 \mathrm{mg} / 100 \mathrm{ml})$. This difference was not significant, and there was no significant difference between the creatinine concentrations in the surgical group (table III).

\section{PLASMA CALCIUM CONCENTRATION}

The mean plasma calcium concentration at diagnosis was $2.88 \mathrm{mmol} / 1$ $(11.5 \mathrm{mg} / 100 \mathrm{ml})$ in the group treated medically; the concentration did not change significantly (figure). At diagnosis five patients had concentrations above $3.0 \mathrm{mmol} / 1(12.0 \mathrm{mg} / 100 \mathrm{ml})$; in two of these the concentrations subsequently fell to 2.8 and $2.69 \mathrm{mmol} / \mathrm{l}(11.2$ and 
$10.8 \mathrm{mg} / 100 \mathrm{ml}$ ). In one patient aged 65 , the initial concentration was $3.15 \mathrm{mmol} 1(12.6 \mathrm{mg} / 100 \mathrm{ml})$ and 10 years later it was $3.05 \mathrm{mmol} / 1$ $(12.2 \mathrm{mg} 100 \mathrm{ml})$. Two elderly patients had concentrations of 3.3 and $3.38 \mathrm{mmol} / 1(13.2$ and $13.5 \mathrm{mg} / 100 \mathrm{ml})$, and both refused operation. In the first patient the plasma calcium concentration 12 years later was $3.2 \mathrm{mmol} / 1(12.8 \mathrm{mg} / 100 \mathrm{ml})$, and in the second six months later it was $3.19 \mathrm{mmol} / 1(12.76 \mathrm{mg} / 100 \mathrm{ml})$

In only one patient (already mentioned) whose plasma calcium concentration was below $3 \mathrm{mmol} / 1(12 \mathrm{mg} / 100 \mathrm{ml})$ at diagnosis did the concentration subsequently increase to above this level while under observation, from 2.81 to $3.02 \mathrm{mmol} / 1(11.24$ to $12.08 \mathrm{mg}$ / $100 \mathrm{ml}$ ) after two vears. This patient then had a successful operation.

The mean plasma calcium concentration in the surgical group was $3.09 \mathrm{mmol} / 1(12.36 \mathrm{mg} / 100 \mathrm{ml})$ and returned to normal in all patients after operation.

TABLE III-Mean (SEM) plasma creatinine concentration (paired t test within groups, unpaired t test between groups)

\begin{tabular}{lccc}
\multirow{2}{*}{ Group } & \multicolumn{3}{c}{ Plasma creatinine $(u \mathrm{~mol} / 1)$} \\
\cline { 2 - 4 } & At presentation & & At follow up \\
\hline Medical & $93 \cdot 7(5 \cdot 4)$ & NS & $96 \cdot 0(6 \cdot 4)$ \\
Surgical & $102 \cdot 1(3.8)$ & NS & $96 \cdot 4(7 \cdot 7)$ \\
\hline
\end{tabular}

NS = Not significant Conversion: SI to traditional units-Plasma creatinine
$1 \mu \mathrm{mol} / 1=11.3 \mu \mathrm{g} 100 \mathrm{ml}$.

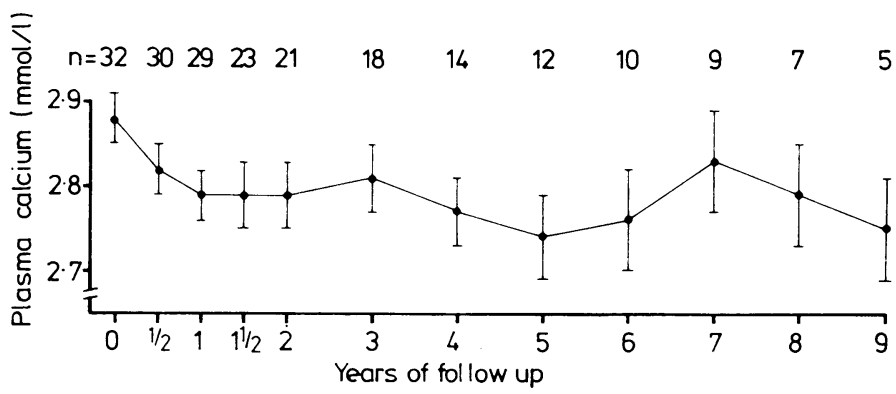

Mean (SEM) plasma calcium concentrations in the patients treated medically. ( $\mathrm{n}$ - Number of patients.)

Conversion: SI to traditional units-Calcium: $1 \mathrm{mmol} / 1 \approx 4 \mathrm{mg} / 100 \mathrm{ml}$.

\section{Discussion}

It is generally agreed that patients with symptoms attributable to primary hyperparathyroidism require operation. Patients diagnosed as having primary hyperparathyroidism after the chance finding of hypercalcaemia who have no symptoms referable to the condition should, however, be considered separately. In the present study there was no significant change in mean plasma calcium and creatinine concentrations or in the proportion of hypertensive patients in the group followed up medically for a mean of $4 \cdot 2$ years.

Although three patients died and the condition of some of the others was only fair, all these patients were elderly and their general condition was poor at the time of diagnosis. In none was it considered that hyperparathyroidism itself had contributed to this. Among the patients who were otherwise fit and might have been considered for operation evidence of deterioration was found in only one, who subsequently had a successful operation because of a rise in plasma calcium concentration.

Until recently, little was known about the natural history of the mild asymptomatic type of primary hyperparathyroidism that now presents a frequent problem in management. Probably the first serious investigation of this condition was at the Mayo Clinic, where a prospective study was started in $1968 .{ }^{13 \cdots 15}$ The main criteria for including patients in that study were a serum calcium concentration of less than $2.75 \mathrm{mmol} / 1(11.0 \mathrm{mg} /$ $100 \mathrm{ml}$ ), normal renal function, no bone disease, no nephrocalcinosis, and no active or infective renal stone disease. At the last follow up, 12 years after the beginning of the study, ${ }^{15}$
33 patients $\left(23^{\circ}\right.$ of the total of 142) had been treated by operation because they no longer fulfilled the criteria: eight had shown a rise in serum calcium concentration; six had developed active stone disease; four had developed bone disease; nine had psychological and various other factors; and in six renal function had decreased. The criterion for a decrease in renal function was a reduction of $10^{\circ}$, or more of baseline creatinine clearance. Whether this is adequate is doubtful, because although five patients were operated on for this reason in the first two and a half years, only one further patient required operation in the next 10 years. If renal function decreases progressively in hyperparathyroidism more patients would be expected to have developed impaired renal function towards the end of the study.

In Sydney 15 patients diagnosed as having primary hyperparathyroidism who had had unsuccessful operations and a further 30 patients who had not had operations were followed up for a mean of three years. ${ }^{16}$ Renal function did not deteriorate in any of these patients, and none required operation because of a further rise in serum calcium concentration. In the United Kingdom Adams followed up 31 patients with hyperparathyroidism for a mean of four years. ${ }^{17}$ There was no significant change in the mean serum creatinine concentration during the period of observation, but one patient had an operation because of a rise in serum calcium concentration. In Derby 39 patients with primary hyperparathyroidism were followed up for a mean of 2.5 years, during which time there was no significant change in mean plasma calcium or creatinine concentration (J S Harrop et al, unpublished findings).

In Sweden Christensson followed up 23 patients with primary hyperparathyroidism found during a routine screening of 16000 subjects and compared them with a group with normocalcaemia matched for age and sex. ${ }^{1 \times}$ There was no further rise in hypercalcaemia in the group with hyperparathyroidism during a 10 year period of observation. Christensson did find appreciably higher systolic and diastolic blood pressures in the hypercalcaemic compared with the normocalcaemic group. Apart from the increase in blood pressure expected with age there was no further rise in blood pressure in the hypercalcaemic group over the 10 years.

In none of the other studies was blood pressure analysed. This may well have been due to the problem of categorising patients receiving hypotensive treatment, which makes statistical analysis difficult. In view of the association between hypertension and hyperparathyroidism, however, we thought that this should nevertheless be attempted. Although there was an increase in the number of patients with hypertension in the medical group during the period of follow up, this did not achieve significance, but the numbers studied were relatively small. However, no decrease occurred in the number of patients with hypertension in the surgical group over a mean period of 5.9 years after successful operation. This suggests that raised blood pressure per se in primary hyperparathyroidism is probably not an indication for operation.

Renal glomerular function as judged by plasma creatinine concentration did not change significantly during the follow up period in our medical group or in three similar series from Australia and this country ${ }^{1617}$ ( $\mathrm{J} \mathrm{S}$ Harrop et al, unpublished findings). There was also no significant change in creatinine concentration in our surgical group. We conclude from our own work and from similar studies that renal glomerular function is not likely to deteriorate in mild primary hyperparathyroidism.

The plasma calcium concentration rose in eight of 142 patients over 12 years in the Mayo Clinic study. ${ }^{15}$ The incidences in the present and four other series were lower, but follow up periods were shorter. All patients who do not have parathyroid surgery should be seen at regular intervals, and if the plasma calcium concentration increases above a level that is considered to be reasonable then operation can be performed. There is no good evidence that the period of observation has any adverse effect on blood pressure or renal function.

One further aspect requires attention-namely, bone in- 
volvement in mild primary hyperparathyroidism. It is possible, although at present uncertain, that mild hyperparathyroidism may affect bone metabolism and perhaps osteoporosis. ${ }^{19}$ This is relevant because most patients with mild asymptomatic hyperparathyroidism are elderly women, who are particularly prone to osteoporosis.

More patients need to be followed up for longer periods before confident guidelines can be laid down. At present, however, we are managing medically patients with primary hyperparathyroidism who have no symptoms referable to the condition and no evidence of bone disease or recurrent renal stones. We consider it wise to advise operation if the plasma calcium concentration is greater than $3 \mathrm{mmol} / \mathrm{l}$ and also in younger patients. We have not established age limits, but we are reasonably confident that medical management is satisfactory for patients over 60 though less so for patients under 50 years. With the passage of time we are now tending also to observe patients over 50 .

We thank Dr D A Heath and Professor J L H O'Riordan for assays of parathyroid hormone; Mr J G Gray, who performed the operations; and $\mathrm{Mr}$ A Lawton for statistical advice. We are indebted to Mrs J Vernon for secretarial help.

\section{References}

${ }^{1}$ Haff RC, Black WC, Ballinger WF. Primary hyperparathyroidism changing clinical, surgical and pathologic aspects. Ann Surg 1970; $171: 85-92$.

2 Boonstra CE, Jackson CE. Serum calcium survey for hyperparathyroidism (results in 50000 clinic patients). Am f Clin Pathol 1971;55:523-6.

${ }^{3}$ Harrop JS, Bailey JE, Woodhead JS. Incidence of hypercalcaemia and primary hyperparathyroidism in relation to the biochemical profile. f Clin Pathol 1982;35:395-400.
'Heath H III, Hodgson SF, Kennedy MA. Primary hyperparathyroidism: incidence, morbidity, and potential economic impact in a community. N Engl f Med 1980;302:189-93.

" Mundy GR, Cove DH, Fisken R, Heath DA, Somers S. Primary hyperparathyroidism: changes in the pattern of clinical presentation. Lancet 1980;i:1317-20.

"Anonymous [Editorial]. Diagnosis and treatment of primary hyperparathyroidism. Lancet $1980 ; \mathrm{i}: 1339-40$.

Wang C-A. Surgery of the parathyroid glands. Adv Surg 1971;5:109-27.

Russell CF, Edis AJ. Surgery for primary hyperparathyroidism: experience with 500 consecutive cases and evaluation of the role of surgery in the asymptomatic patient. Br 7 Surg 1982;69:244-7.

${ }^{9}$ George JM, Rabson AS, Ketcham A, Bartter FC. Calcareous renal disease and hyperparathyroidism. Qf Med 1965;34:291-301.

1" Hamilton M, Pickering GW, Roberts JAF, Sowry GSC. The aetiology of essential hypertension. 1. The arterial pressure in the general population. Clin $S_{c i} 1954 ; 13: 11-35$.

${ }^{11}$ Bjornsson TD. Use of serum creatinine concentrations to determine renal function. Clin Pharmacokinet 1979;4:200-22.

1.2 Thomis JA, Soep HH, Hallynk T, Boelaert J, Daneels R, Dettli L. Creatinine clearance, different methods of determination. $\mathrm{Br} . \mathrm{F}$ Clin Pharmacol $1982 ; 13: 260$.

${ }^{13}$ Purnell DC, Smith LH, Scholz DA, Elveback LR, Arnaud CD. Primary hyperparathyroidism: a prospective clinical study. Am f Med 1971; $50: 670-8$.

1 Purnell DC, Scholz DA, Smith LH, et al. Treatment of primary hyperparathyroidism. Am f Med 1974;56:800-9.

${ }^{15}$ Scholz DA, Purnell DC. Asymptomatic primary hyperparathyroidism. Mayo Clin Proc $1981 ; \mathbf{5 6}: 473-8$.

${ }^{16}$ Rohl PG, Wilkinson M, Clifton-Bligh P, Posen S. Hyperparathyroidism: experiences with treated and untreated patients. Med f Aust 1981;1 519-21.

17 Adams PH. Conservative management of primary hyperparathyroidism. 7 R Coll Physicians Lond 1982;16:184-90.

is Christensson $T$. Parathyroid hypertension. Br Med f 1983;286:1899.

${ }^{19}$ Heath H III, Purnell DC. Asymptomatic hypercalcaemia and primary hyperparathyroidism. In: Heath DA, Marx SJ, eds Clinical endocrinology. 2 Calcium disorders. London: Butterworth, 1982:189-216.

(Accepted 26 August 1983)

\title{
Individual contributions to multiauthor papers
}

\author{
S D MOULOPOULOS, D A SIDERIS, K A GEORGILIS
}

\begin{abstract}
The curricula vitae of four candidates for a professorial appointment at Athens University were examined to estimate the actual contribution of each candidate to the papers of which he was a coauthor. A total of 879 research papers by the four candidates were analysed in terms of the number of authors, the sequence of names, and the year of publication. The four authors presented $364,349,96$, and 70 papers. If an equal contribution of all
\end{abstract}

Department of Clinical Therapeutics, Medical School of Athens University

$S \mathrm{D}$ MOULOPOULOS, $\mathrm{MD}$, professor (original idea, planning, comments) $\mathrm{D}$ A SIDERIS, MD, associate professor (planning, evaluation of data $90^{\circ}$ ", writing up)

K A GEORGILIS, MD, intern (collection of data, evaluation of data $10^{\circ}{ }_{11}$ )

Correspondence to: Assistant Professor D A Sideris, MD, Department of Clinical Therapeutics, University of Athens Medical School, V Sofias and $\mathrm{K}$ Lourou str, Athens 11528, Greece. coauthors is assumed, the actual number of papers (all papers divided by the number of authors), is about 106 , 83,28 , and 26 , respectively, so that the rank of the four candidates did not change. On the assumption that the contribution was related to the candidate's position in the order of the coauthors' names, the numbers of papers were corrected to $84,95,26,33$ using one statistical method and to $88,94,28,31$ using another. These assumptions may not be valid, however, especially as the last author may be more important than the intermediate ones.

It is suggested that the journals require authors to state their specific contribution to a paper, such as original idea, planning, collecting data, writing up, etc.

\section{Introduction}

Multiauthorship leads to problems of indexing and an increase in the number of published papers, ${ }^{1}$ and has been attributed to overpopulation, desire for promotion, multi-institutional or multidisciplinary trials, and the ease of including authors 